\title{
Orbital dermo-lipoma with Goldenhar's syndrome and exophthalmos
}

\author{
ALY MORTADA \\ Department of Ophthalmology, Faculty of Medicine, Cairo University, Egypt
}

Goldenhar (1952) described a syndrome characterized by epibulbar dermoids, auricular appendages, and auricular fistulae. The three following cases are described because in them Goldenhar's syndrome was accompanied by mild proptosis (Table).

Table Particulars of three cases

\begin{tabular}{|c|c|c|c|c|c|}
\hline Case no. & $\begin{array}{l}\text { Age } \\
(y r s)\end{array}$ & - $\quad S e x$ & Side affected & $\begin{array}{l}\text { Proptosis (mm.) } \\
(\text { Hyrtel) }\end{array}$ & Histopathology \\
\hline $\mathbf{I}$ & 14 & $\mathbf{F}$ & Left & 4 (Fig. I) & Figs 2 and 3 \\
\hline 2 & 3 & $\mathbf{M}$ & Right & 3 (Figs 4 and 5) & Fig. 6 \\
\hline 3 & 2 & $\mathbf{M}$ & Left & 3 (Fig. 7) & Fig. 8 \\
\hline
\end{tabular}

Case reports (see Figs I to 8, opposite and overleaf)

The general condition of the patients was good and the ocular fundi were normal. Dermo-lipomata of the affected bulbar conjunctivae extending into the orbit and causing proptosis had been present since birth. All showed accessory auricular appendages and auricular fistulae. Case 3 also showed mandibulo-facial dysostosis, coloboma of the left upper lid, and microcornea of the right eye.

\section{Discussion}

A dermo-lipoma is a congenital lesion (Reese, 1963). There is no indication that epibulbar dermoids are hereditary in man (François, 196I; Waardenburg, Franceschetti, and Klein, I96r). Goldenhar (1952) and Duke-Elder (1964) have pointed out that dermoids and dermo-lipomata often accompany other congenital abnormalities, including auricular appendages, fistula auris congenita, coloboma of the iris and choroid, and macrostomia. Superior palpebral coloboma and microcornea may also be present, as in the third case presented here.

Epibulbar dermoids accompanied by mandibulo-facial dysostosis have been described by Jorio (1948), Tranou-Sfalangacou and Velissaropoulos (195I), and Paufique, Etienne, and Moreau (1952). Blodi (1957) described a case of Goldenhar's syndrome with mandibulo-facial dysostosis.

In the three cases described here there was also proptosis of the eye affected by the dermo-lipoma. 


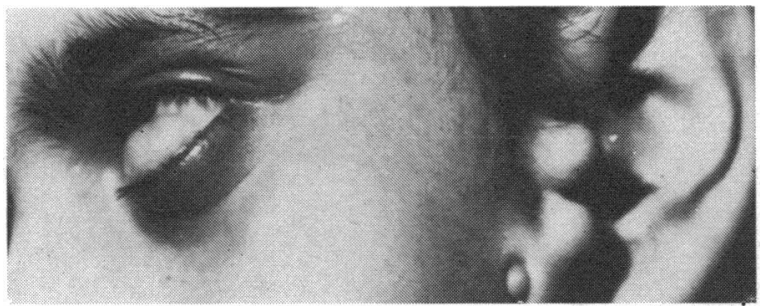

FIG. I Case I. Dermo-lipoma of left lower part of cornea and bulbar conjunctiva extending to orbit present since birth, causing proptosis in a girl aged 14 years. There was also a solid dermoid in the right outer limbus. Two accessory auricular appendages and an aural fistula are seen in front of the left ear (Goldenhar's syndrome)

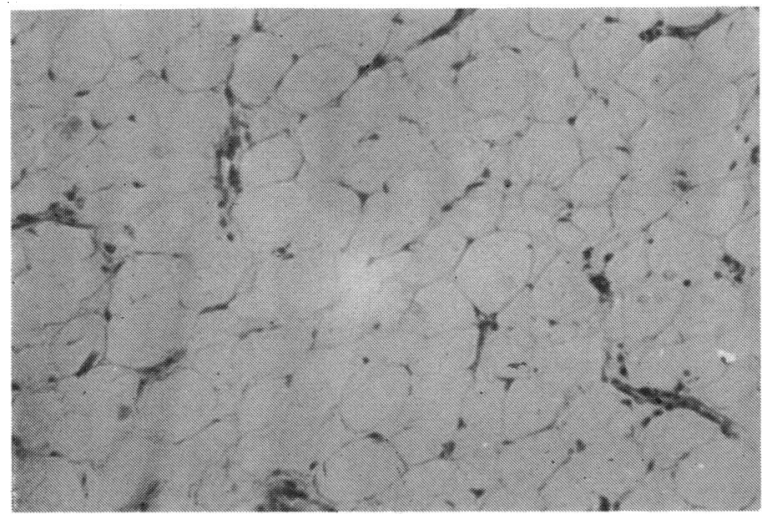

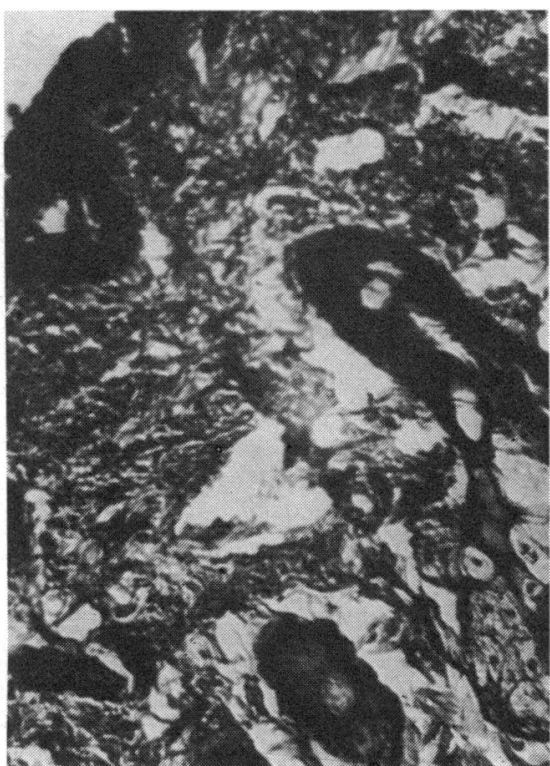

FIG. 2 Case I. Dermo-lipoma, showing skin on external surface, and dermis containing sebaceous and sweat glands and hair follicles. The dermo-lipoma extension into the orbit showed fibro-fatty tissue. $\quad \times 100$

FIg. 3 Case I. Dermo-lipoma, showing extension into the orbit. $\times 100$

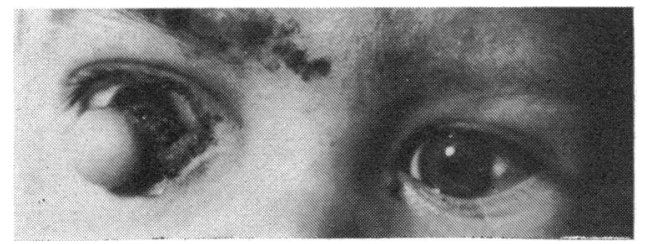

FIG. 4 Case 2. Dermo-lipoma of right lower outer part of cornea and bulbar conjunctiva extending into the orbit, present since birth and causing proptosis in $a$ boy aged 3 years. There were also three accessory auricular appendages and an aural fistula in front of the right ear (Goldenhar's syndrome)

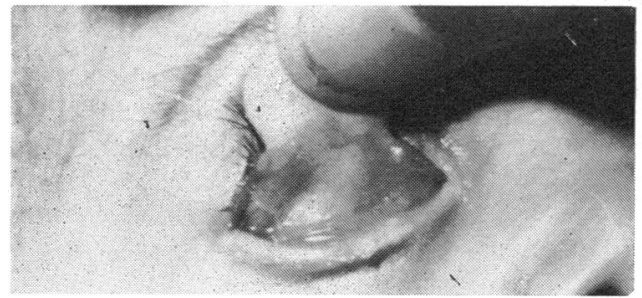

FIG. 5 Case 2. Extension of dermo-lipoma onto right lower bulbar conjunctiva and orbit

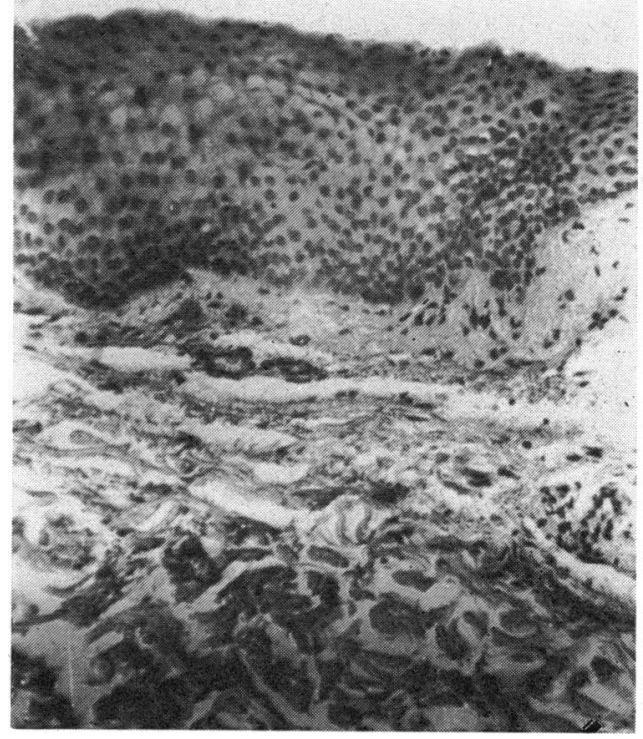

FIG. 6 Case 2. Dermo-lipoma (as in Fig. 5), showing stratified epithelium and dermis of fibrous tissue containing muscle fibres. $\quad \times 120$ 


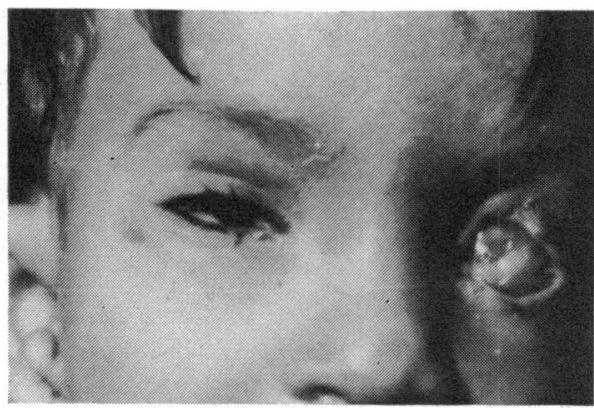

Fig. 7 Case 3. Dermo-lipoma of left lower bulbar conjunctiva, coming in front of the cornea and extending to the orbit, present since birth and causing proptosis in a boy aged 2 years. In front of the right ear there were an accessory auricular appendage and aural fistula (Goldenhar's syndrome). Coloboma of the left upper lid, right microcornea, a solid dermoid of the right lower limbus, and mandibulo-facial dystosis were also present

FIG. 8 Case 3. Stratified epithelium on surface of dermo-lipoma seen in Fig. 7. $\times 120$

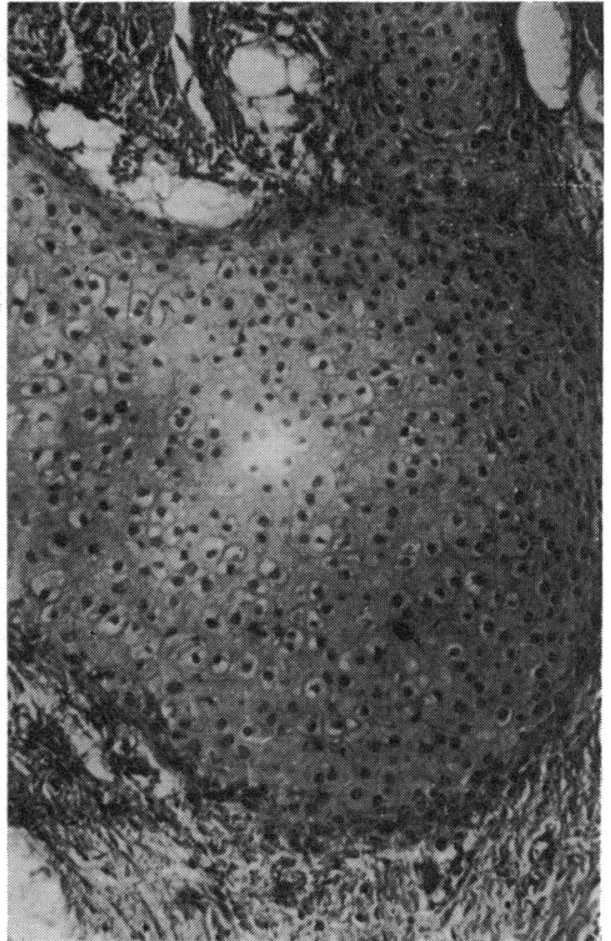

\section{Summary}

(x) Three cases of Goldenhar's syndrome are described in which the eye affected by the dermo-lipoma also showed mild proptosis.

(2) The third case also showed mandibulo-facial dysostosis.

(3) These are the first three cases of Goldenhar's syndrome to be reported from Egypt.

\section{References}

BLodi, p. c. (1957) A.M.A. Arch. Ophthal., 57, 593

DUKE-ELDER, s. (1964) "System of Ophthalmology", vol. 3, "Normal and Abnormal Development", pt. 2, "Congenital Deformities", p. 822. Kimpton, London

FRANçoIs, J. (1961) "Heredity in Ophthalmology", p. 288. Mosby, St. Louis GOLDENhaR, M. (1952) 7. Génét. hum., r, 243

JORIO, s. (1948) Rass. ital. Ottal., 17, 289

PAUfiQue, L., ETIENNE, R., and MOREAU, P. G. (1952) Bull. Soc. Ophtal. Fr., p. 81

REESE, A. B. (1963) "Tumors of the Eye", 2nd ed., p. 5 10. Harper and Row, New York, Evanston, and London

tranou-Sfalangacou, L., and velissaropoulos, P. (195I) Bull. Soc. hellén. Ophtal., 19, 449

WAARdenBURG, P. J., FRANCeschetti, A., and KLein, D. (1961) "Genetics and Ophthalmology", vol. I, p. 282. Royal VanGorcum, Assen, Netherlands (and Blackwell, Oxford; Thomas, Springfield, Ill.) 